\title{
Numerical Study of Damage Modes and Damage Assessment of CFST Columns under Blast Loading
}

\author{
Junhao Zhang, ${ }^{1}$ Shiyong Jiang, ${ }^{1}$ Bin Chen, ${ }^{2}$ Chunhai Li, ${ }^{3}$ and Hao Qin ${ }^{3}$ \\ ${ }^{1}$ Chongqing Key Laboratory of Geomechanics \& Geoenvironmental Protection, Logistical Engineering University, \\ Chongqing 401311, China \\ ${ }^{2}$ Institute of Engineering Mechanics, China Earthquake Administration, Harbin 150080, China \\ ${ }^{3}$ Beijing Canbao Institute of Architectural Design, Beijing 100850, China
}

Correspondence should be addressed to Shiyong Jiang; jiangshy1@163.com

Received 2 September 2015; Revised 22 November 2015; Accepted 24 November 2015

Academic Editor: Sakdirat Kaewunruen

Copyright (C) 2016 Junhao Zhang et al. This is an open access article distributed under the Creative Commons Attribution License, which permits unrestricted use, distribution, and reproduction in any medium, provided the original work is properly cited.

Columns of frame structures are the key load-bearing components and the exterior columns are susceptible to attack in terrorist blasts. When subjected to blast loads, the columns would suffer a loss of bearing capacity to a certain extent due to the damage imparted, which may induce the collapse of them and even cause the progressive collapse of the whole structure. In this paper, the high-fidelity physics-based finite element program LS-DYNA was utilized to investigate the dynamic behavior and damage characteristics of the widely used concrete-filled steel tube (CFST) columns subjected to blast loads. The established numerical model was calibrated with test data in open literatures. Possible damage modes of CFST columns under blast loading were analyzed, and the damage criterion based on the residual axial load capacity of the columns was adopted to assess the damage degree. A parametric study was conducted to investigate the effects of critical parameters such as blast conditions and column details on the damage degree of CFST columns. Based on the numerical simulation data, an empirical equation was proposed to estimate the variation of columns damage degree with the various parameters.

\section{Introduction}

Concrete-filled steel tube (CFST) columns have been widely used in engineering structures such as high-rise buildings, arch bridges, and factories, as they have advantages of high strength and excellent ductility due to a confinement effect and a changed buckling mode $[1,2]$. With the increase of terrorist bombings in recent years, blast resistance of the structures has become a consideration in their design process [3]. When subjected to blast loads, columns may suffer a loss of bearing capacity to a certain extent due to the damage imparted, which may induce the collapse of the columns and even cause the progressive collapse of the whole structure. In addition, both concrete and steel, of which CFST columns are composed, may respond to blast loads at very high strain rates in the order of $1-100 \mathrm{~s}^{-1}$ or even higher, thus making the dynamic analysis of the CFST columns different from that under static loads and earthquake actions. Therefore, it is of realistic significance to study the dynamic behavior and damage characteristics of CFST columns under blast loading.

Fujikura et al. experimentally investigated the dynamic responses of CFST bridge pier column specimens under blast loading. According to the magnitude of the support rotation, the damage states of the column specimens were categorized into three types, that is, the plastic deformation, onset of fracture, and postfracture. The authors also compared the maximum response of the specimens obtained from the simplified method based on the equivalent single-degree-offreedom (SDOF) theory with the test data $[4,5]$. Li et al. studied the dynamic behavior of CFST columns through a series of field blast experiments. They analyzed the effects of explosive mass, standoff distance, axial load ratio, concrete strength grade, and steel ratio on the displacement and strain responses of CFST columns which showed global-mode controlled responses in the tests [6]. Remennikov and Uy carried out field tests on the CFST specimens and demonstrated the 


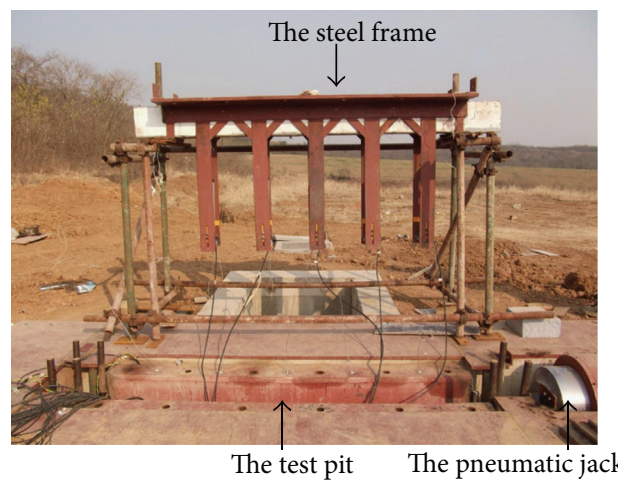

(a) The steel frame that holds the specimen in place

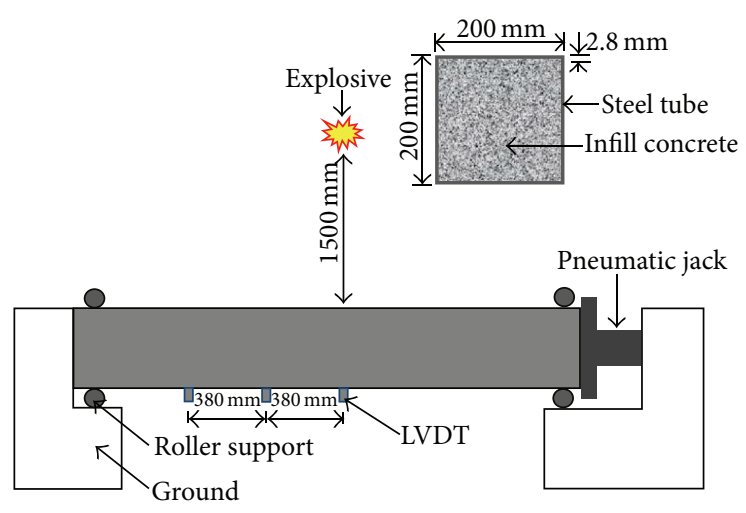

(b) The test configuration

FIGURE 1: Test setup (Zhang et al. [9]).

effects of scaled standoff distance on the mode of response and failure of the specimens under near-field blast loading. It was found that CFST members may suffer severe localized damage due to the highly localized blast impulse when the explosive was located quite close to the test members. The authors also developed a simplified engineering-level model for prediction of the mid-span deflection history of the CFST member [7]. Ngo et al. utilized the coupled Arbitrary Lagrange Euler (ALE) blast wave-structure interaction algorithms and numerically investigated the failure patterns, deformation histories, and energy absorption characteristics of CFST members subjected to near-field blast loading. Two distinct phases of deformation were identified in the study, of which the local deformation that initially occurred rather than the flexural global deformation that followed dominates the energy absorption history of the column specimen [8]. Zhang et al. carried out blast tests and finite element simulations on the axially compressed CFST column members. Results indicated that CFST columns showed good resistance against flexural loads under blast loading. The energies absorbed by local deformation and flexural deformation of the column during the blast loading were also investigated, and it was found that the majority of the energies were absorbed by global deformation when the mode of response was mainly flexural [9]. The authors also investigated the dynamic responses and damage characteristics of the concrete-filled columns with double-skin tubes to blast loads, and the critical parameters that affect the displacement time histories of the columns were analyzed [10].

The review of these literatures indicates that the mode of response and damage criterion are key issues in understanding the dynamic behavior and damage characteristics of CFST columns subjected to blast loads, as some damage criterions are only applicable to certain damage mode of the columns and different conclusions may be drawn under varied damage modes as stated previously. The objective of this paper is to study the damage modes and damage assessment of CFST columns under blast loading. The numerical model is established using the finite element program LS-DYNA and calibrated with correlated experimental studies by other researchers. Possible damage modes of the columns subjected to blast loads are analyzed, and the criterion suitable to assess the degree of the columns damage is adopted accordingly. Parameters that may affect the damage degree of the columns are analyzed in the study; they are blast condition, column dimension, steel ratio, and axial load ratio, which are then incorporated into a proposed equation, capable of estimating the damage degree of CFST columns based on the numerical results.

\section{Numerical Model Calibration}

The high-fidelity physics-based finite element program LSDYNA was used in the paper. To calibrate the employed numerical models for simulating the dynamic responses of CFST columns to blast loads, one of the blast tests on CFST columns conducted by Zhang et al. [9] was simulated and a comparison was made between the test and numerical simulation results. Figure 1 shows the sketch of test setup of column number S4. The dimensions of the column are $2500 \mathrm{~mm}$ (height) $\times 200 \mathrm{~mm}$ (width) $\times 200 \mathrm{~mm}$ (depth), with the tube thickness of $2.8 \mathrm{~mm}$. The yield stress, ultimate stress, Young's modulus, and elongation of the steel tube are 358.2 $\mathrm{MPa}, 437.4 \mathrm{MPa}, 202.6 \mathrm{GPa}$, and $21.3 \%$, respectively. The average cubic compressive strength of the infill concrete is $47.4 \mathrm{MPa}$ which is $37.9 \mathrm{MPa}$ if converted to cylindrical compressive strength. During the test, the specimen was firstly placed on a steel frame which was then placed into the test pit. The specimen was simply supported by four rollers (two at each ends); thus the effective span of it was $2300 \mathrm{~mm}$. A steel plate was placed between the roller and the column to avoid stress concentration. The initial axial load ( $514 \mathrm{kN})$ was applied to the ends of the column through a pneumatic jack prior to blast loading, and then $50 \mathrm{~kg}$ of emulsion explosive (equivalent to $35 \mathrm{~kg}$ of TNT) was ignited in the air at a standoff distance (center of explosive to the mid of column front surface) of $1500 \mathrm{~mm}$ to generate the blast environment.

\subsection{Numerical Model}

2.1.1. Material Model. Considering the large strain and high strain rate problems involved in analyzing the responses of 


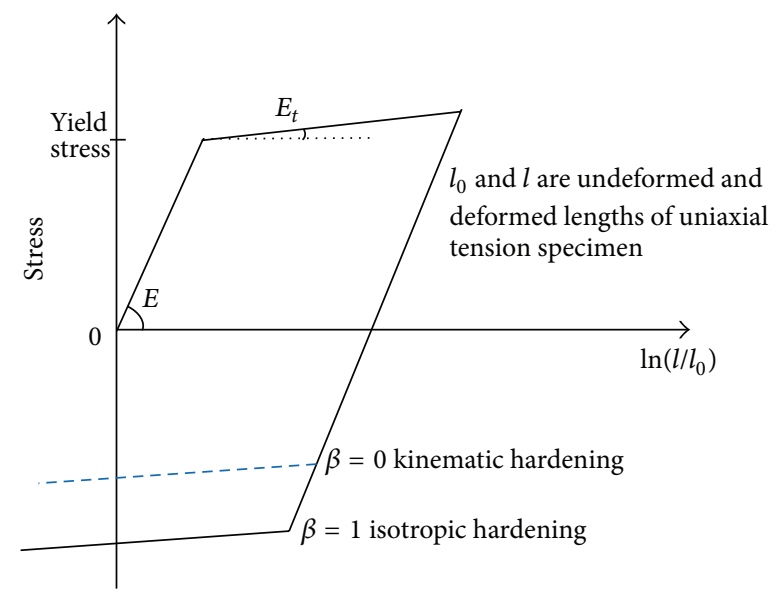

FIGURE 2: Plastic kinematic model for steel modeling.

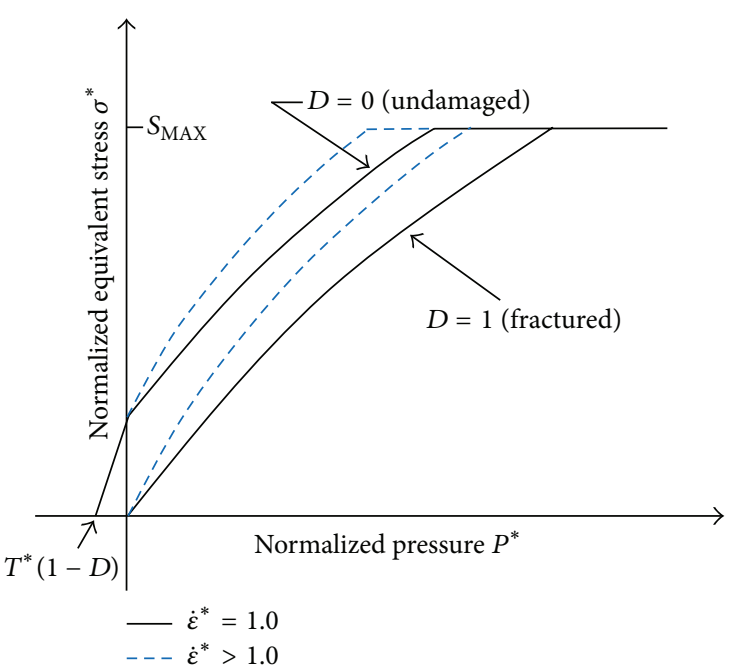

FIGURE 3: JHC model for concrete modeling.

The accumulated damage is expressed as

$$
D=\sum \frac{\Delta \varepsilon_{P}+\Delta \mu_{P}}{D_{1}\left(P^{*}+T^{*}\right)^{D_{2}}},
$$

where $\Delta \varepsilon_{P}$ and $\Delta \mu_{P}$ are the equivalent plastic strain and plastic volumetric strain, respectively; $D_{1}$ and $D_{2}$ are damage constants, and $T^{*}=T / f_{c}^{\prime}$ is the dimensionless tensile hydrostatic pressure.

The relation between pressure and volumetric strain is defined as

$$
P= \begin{cases}K_{e} \mu, & 0 \leq P<P_{C} \\ P_{C}+K_{C}\left(\mu-\mu_{C}\right), & P_{C} \leq P<P_{L} \\ K_{1} \bar{\mu}+K_{2} \bar{\mu}^{2}+K_{3} \bar{\mu}^{3}, & P \geq P_{L},\end{cases}
$$

where $K_{e}$ is the elastic bulk modulus, $K_{e}=P_{C} / \mu_{C}$, and $P_{C}$ and $\mu_{C}$ are the pressure and volumetric strain when crushing occurs in concrete, $\mu$ is the volumetric strain, $\bar{\mu}=\left(\mu-\mu_{L}\right) /(1+$ $\left.\mu_{L}\right)$ is the corrected volumetric strain, and $P_{L}$ and $\mu_{L}$ are the locking pressure and volumetric strain at the beginning of the fully compacted stage $\left(P \geq P_{L}\right) ; K_{1}, K_{2}$, and $K_{3}$ are material constants of concrete.

The reliability of this concrete model in predicting the responses of concrete structures to blast loads has been demonstrated by many researchers $[14,15]$. Material parameters of the infill concrete in the simulation are listed in Table 2.

2.1.2. Finite Element Model and Erosion Algorithm. The Belytschko-Tsay shell element is used in the study to model the steel tube, and the infill concrete is modeled with singlepoint integration solid elements. A mesh size of $25 \mathrm{~mm}$ is selected for the steel tube and infill concrete through a numerical convergence study. It is found that further refinement of element size has little effect on the numerical results but increases the calculation time enormously. A perfect bond between steel tube and infill concrete is assumed in the mum strength, as shown in Figure 3. 
TABLE 1: Material parameters of the steel tube.

\begin{tabular}{lccccccccc}
\hline Parameter & $\begin{array}{c}\text { Mass density } \\
\rho_{1}\left(\mathrm{~kg} / \mathrm{m}^{3}\right)\end{array}$ & Poisson's ratio $v$ & $\sigma_{0}(\mathrm{MPa})$ & $E(\mathrm{GPa})$ & $E_{t}(\mathrm{MPa})$ & $\beta$ & $C$ & $\begin{array}{c}\text { Failure strain } \\
(\mathrm{FS})\end{array}$ \\
\hline Value & 7850 & 0.3 & 358 & 203 & 414 & 0 & 40.4 & 5 & 0.2 \\
\hline
\end{tabular}

TABLE 2: Material parameters of the infill concrete.

\begin{tabular}{|c|c|c|c|c|c|c|c|}
\hline Parameter & $\begin{array}{c}\text { Mass density } \\
\rho_{2}\left(\mathrm{~kg} / \mathrm{m}^{3}\right)\end{array}$ & $A$ & $B$ & $C$ & $N$ & $f_{c}^{\prime}(\mathrm{MPa})$ & $S_{\mathrm{MAX}}$ \\
\hline Value & 2440 & 0.79 & 1.60 & 0.007 & 0.61 & 37.9 & 7.0 \\
\hline Parameter & $\begin{array}{l}\text { Shear modulus } \\
\qquad G(\mathrm{GPa})\end{array}$ & $\begin{array}{c}\text { Maximum } \\
\text { tensile pressure } \\
T(\mathrm{MPa}) \\
\end{array}$ & $\begin{array}{l}\text { Threshold } \\
\text { strain rate } \\
\text { EPS0 }\left(\mathrm{s}^{-1}\right)\end{array}$ & $\begin{array}{l}\text { Plastic strain } \\
\text { before fracture } \\
\text { EFMIN }\end{array}$ & $\begin{array}{l}\text { Crushing } \\
\text { pressure } \\
P_{\mathrm{C}}(\mathrm{MPa})\end{array}$ & $\begin{array}{c}\text { Crushing } \\
\text { volumetric } \\
\text { strain } U_{C} \\
\end{array}$ & $\begin{array}{l}\text { Locking } \\
\text { pressure } \\
P_{L}(\mathrm{MPa})\end{array}$ \\
\hline Value & 14.86 & 4.0 & 1.0 & 0.01 & 16 & 0.001 & 800 \\
\hline Parameter & $\begin{array}{l}\text { Locking } \\
\text { volumetric } \\
\text { strain } U_{L} \\
\end{array}$ & $\begin{array}{c}\text { Damage } \\
\text { constant } \\
D_{1} \\
\end{array}$ & $\begin{array}{c}\text { Damage } \\
\text { constant } \\
D_{2} \\
\end{array}$ & $\begin{array}{l}\text { Pressure } \\
\text { constant } \\
K_{1}(\mathrm{GPa}) \\
\end{array}$ & $\begin{array}{l}\text { Pressure } \\
\text { constant } \\
K_{2}(\mathrm{GPa}) \\
\end{array}$ & $\begin{array}{l}\text { Pressure } \\
\text { constant } \\
K_{3}(\mathrm{GPa}) \\
\end{array}$ & \\
\hline Value & 0.1 & 0.04 & 1.0 & 85 & -171 & 208 & \\
\hline
\end{tabular}

numerical study since no researches have reported a noticeable debond between the two materials in blast tests. In order to simulate the physical fracture, shear failure, and crushing of the concrete under blast loading, the erosion algorithm is used to account for concrete failure. Considering the strain rate effect on the concrete strength, the erosion criterion based on the principle strain is often used [16]. A number of simulations are carried out with different erosion criteria, and it is found that using principle tensile strain of 0.01 as the erosion criterion, which is also used by Ngo et al. [8], leads to reliable predictions of the responses of CFST columns.

\subsubsection{Sequence of Loads Application and Blast Load Modelling.} In order to simulate the real stress state of CFST columns, the linearly increasing axial quasi-static loads up to the service axial load level are applied to the top of the column prior to blast loading through the implicit solver. To avoid too much oscillation of the column, the time duration for increasing the loads from zero to full service level is $150 \mathrm{~ms}$. Then, the computational algorithm switches from implicit to explicit, and the blast loads are applied over the front surface of the column with the axial loads unchanged.

Blast loads are generated using the ConWep air blast model [17], that is, Load Blast Enhanced in LS-DYNA [18]. Compared to other techniques, that is, the Arbitrary Lagrangian Eulerian (ALE) methodology, this model is more computationally efficient to simulate blast loads with a high level of accuracy. While similar to the model Load Blast, it also includes enhancements for treating reflected waves. The loading face of the column is predefined before the generation of blast loads, and the time history of blast loads acting on each segment is calculated through ConWep formula as follows:

$$
P(t)=P_{r}(t) \cos ^{2} \theta+P_{i}(t)\left(1+\cos ^{2} \theta-2 \cos \theta\right),
$$

where $P(t)$ is the reflected overpressure on the defined load segment at moment $t, P_{r}(t)$ and $P_{i}(t)$ are the normal

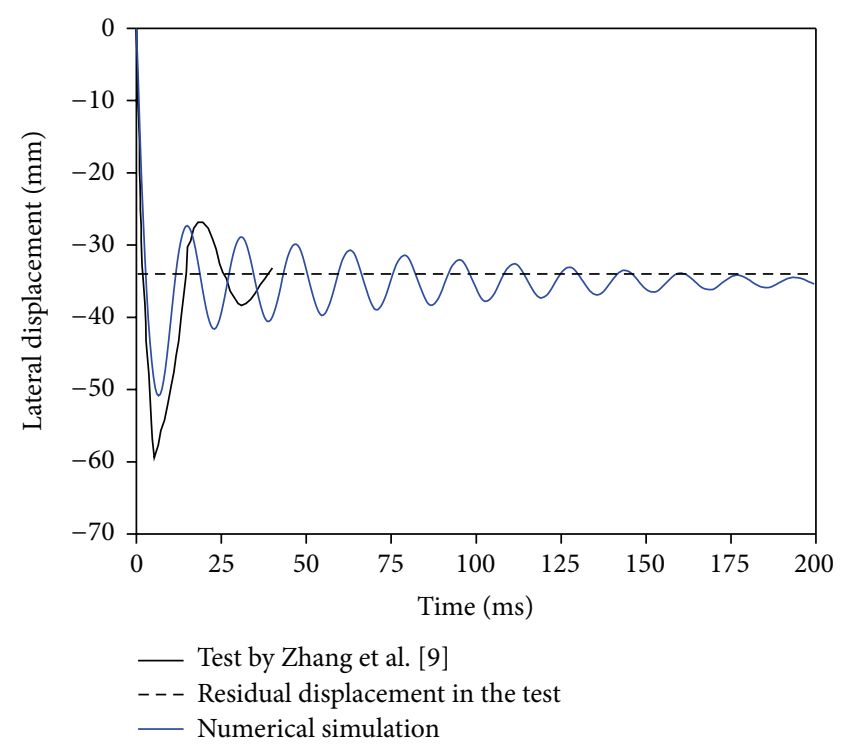

FIGURE 4: Comparison of the displacement data from test and that of numerical simulation.

reflected overpressure and incident overpressure at moment $t$, respectively, and $\theta$ is the angle of incidence of the blast wave.

2.2. Model Calibration and Discussion. Numerical simulations of the blast test were carried out and the dynamic response and damage mode of column S4 were obtained. Since the recording of LVDT1 at the center of column S4 was missing in the test, the value of LVDT2 (see Figure 1(b)) at $380 \mathrm{~mm}$ from the center of the column was used to calibrate the numerical model. Comparison of the calculated displacement time history with test results is shown in Figure 4. It is found that the peak displacement of numerical results $(50.9 \mathrm{~mm})$ is smaller than that in the test $(60 \mathrm{~mm})$ while the numerical residual displacement $(35.4 \mathrm{~mm})$ is slightly larger than the test value $(34 \mathrm{~mm})$. Several factors as follows may 


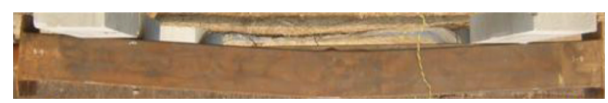

(a) Test result (Zhang et al. [9])

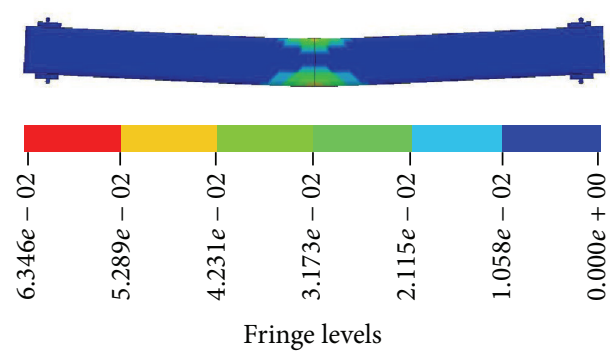

(b) Numerical result

FIGURE 5: Comparison of the column damage mode in the test and that from numerical simulation.

account for such discrepancies: (1) the difference between the actual support condition which is not rigid enough and those adopted in the simulation; (2) ignorance of the potential loss of axial loads and reduction of flexural resistance considering the detachment of the column ends from the loading device in the test; and (3) the limitations of material models in depicting the real-time nonlinear behaviors of steel and concrete during test. Although discrepancies exist between the simulation and test values, the largest error with respect to the maximum displacements is within $15.2 \%$. Figure 5 shows the comparison of the damage mode of the column in the test and that from the numerical simulation presented in effective plastic strain contour, and good agreement is observed in between. These results demonstrate that the calibrated numerical model leads to reasonable predictions of the dynamic responses and damage modes of CFST columns to blast loads and can be used for the subsequent study.

\section{Damage Modes of CFST Column under Blast Loading}

3.1. Column Configuration. The above calibrated numerical model is utilized herein to simulate dynamic behavior and possible damage modes of CFST column under blast loading. The column is designed based on the specifications provided by Chinese Standard CECS 159: 2004 [19]. As shown in Figure 6 , the dimensions of the column are $h$ (height) $\times$ $w($ width $) \times d($ depth $)=3700 \mathrm{~mm} \times 600 \mathrm{~mm} \times 600 \mathrm{~mm}$, with the tube thickness of $18 \mathrm{~mm}$. Parameters of the steel tube and the infill concrete used in the simulation are the same as those in Section 2. In order to simulate the real life boundary conditions for CFST columns, a column head and a footing are considered in the numerical model. The outer vertical face of the footing and head are constrained against horizontal motions and the bottom face of the footing is constrained against vertical motions [20]. Horizontal distance from the charge center to the column front surface, that is, the standoff distance, is denoted as $X$. And the vertical distance from the charge center to the ground, that is, the height of burst, is denoted as $H_{B}$. The initial dead weight imposed on the
TABle 3: Possible damage modes of the CFST column.

\begin{tabular}{lccc}
\hline$M(\mathrm{~kg})$ & $H_{B}(\mathrm{~m})$ & $Z\left(\mathrm{~m} / \mathrm{kg}^{1 / 3}\right)$ & Damage mode \\
\hline \multirow{3}{*}{50} & & $\leq 0.21$ & Localized \\
& 0 & $0.22-0.24$ & Shear \\
& & $\geq 0.26$ & Flexural \\
\hline \multirow{3}{*}{250} & & $\leq 0.25$ & Localized \\
& 0 & $0.30-0.48$ & Shear \\
& & $\geq 0.52$ & Flexural \\
\hline \multirow{2}{*}{50} & \multirow{2}{*}{1.85} & $\leq 0.16$ & Localized \\
& & $\geq 0.18$ & Flexural \\
\hline
\end{tabular}

column is 35 percent of axial load capacity of the undamaged column, which represents the axial load level of a typical ground floor column in a high-rise building.

As the blast load parameters are related to both explosive mass and standoff distance, the scaled standoff distance is introduced to consider their combined effects and is defined as [21]

$$
Z=\frac{X}{M^{1 / 3}}
$$

where $Z$ is the scaled standoff distance and $M$ is the equivalent mass of TNT.

3.2. Possible Damage Modes. Three damage modes of the CFST column under blast loading have been observed through a number of simulations; they are flexural damage, shear damage, and localized damage. Table 3 presents damage modes of the column according to different blast conditions. It is found that, in general, explosive with a small scaled standoff distance favors a localized damage, whilst shear damage and localized damage occur when the explosive is relatively far from the column. This is because the blast loads are highly intensive when the scaled standoff distance is small, and for very local blast loads acting on the column, failure of the infill concrete and steel tube starts before any considerable overall response can occur and the column surfers a localized damage. However, with the increase of scaled standoff distance, blast loads tend to be well-distributed over the surface of the column, which is inclined to response globally and undergo shear damage and flexural damage. Also, the damage mode is affected by the explosive mass, height of burst. Typical results of these damage modes are shown with effective plastic strain contours in Figures 7-9.

Figure 7 shows the flexural damage mode of the CFST column induced by the detonation of $50 \mathrm{~kg}$ of TNT at the scaled standoff distance of $0.18 \mathrm{~m} / \mathrm{kg}^{1 / 3}$ with the height of burst of $1.85 \mathrm{~m}$. In this configuration, when the blast loads acted on the column, the mid-part of it responded immediately with the increment of lateral deformation. Then, the areas near the supports of the column began to deform and rotate. As the global flexural deformation of the column evolved, plastic hinges developed in the mid-part and near the supports of the column where the bending moments were large. 


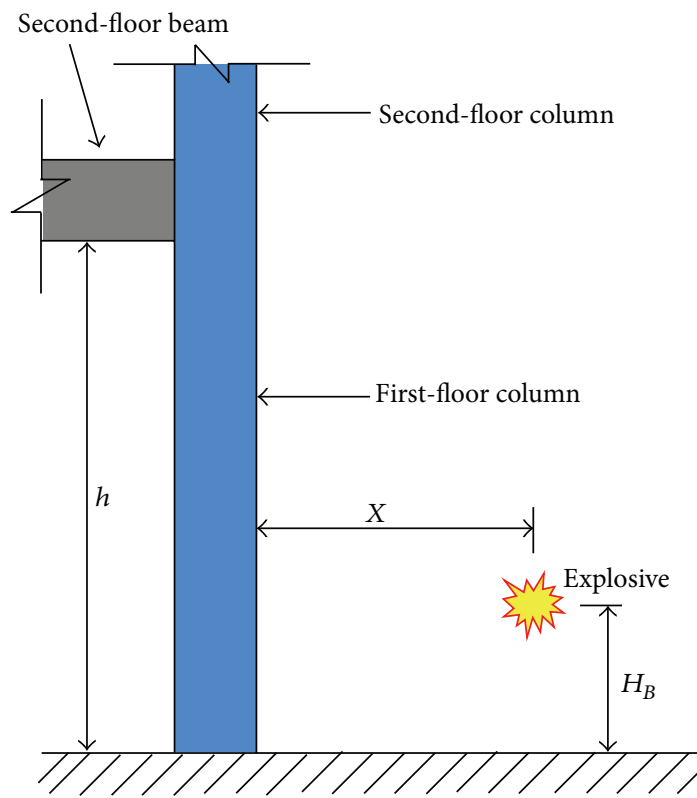

(a) Explosion scenario

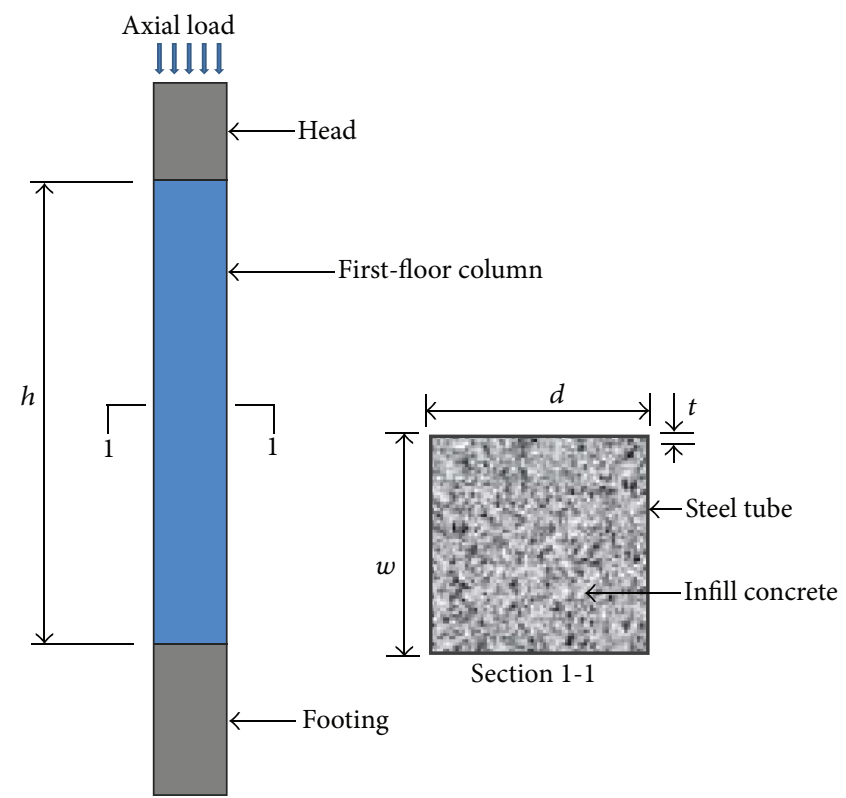

(b) Column details

FIGURE 6: Sketch of the numerical analysis model.

Figure 8 shows the shear damage mode of the column resulted from $250 \mathrm{~kg}$ of TNT detonating on the ground at the scaled standoff distance of $0.33 \mathrm{~m} / \mathrm{kg}^{1 / 3}$. Due to the large shear force and the development of shear deformation near the supports, the infill concrete was sheared off accompanied with the rupture of the steel tube around the cross section of the column. Finally, the column failed in brittle shear before any ductile flexural hinge developed.

As discussed above, flexural damage and shear damage of the column are due to the deformation and internal force of the whole member induced by the blast loads. On the contrary, localized damage of the CFST column is dominated by the deformation and failure of the concrete infill and steel tube in the vicinity of the explosion, whilst other parts of the column remain almost elastic and the global deformation of the column is small.

Figure 9 shows the localized damage mode of the CFST column caused by the detonation of $50 \mathrm{~kg}$ of TNT on the ground with the scaled standoff distance of $0.18 \mathrm{~m} / \mathrm{kg}^{1 / 3}$. When the impulsive shock front of high intensity met the column surface, the stress waves were generated and propagated from the tube front surface towards the concrete infill and the lateral and back surfaces of the tube. Then, the concrete close to the explosion was cracked and crushed, and the front side of the tube which lost the internal support of the concrete fill was squashed with the bulging of its lateral and back sides. As the localized deformation of the column evolved, rupture and local buckling failure of the steel tube took place, yet the global lateral deformation of the column had almost not developed at this moment.

It should be mentioned that these damage modes are only typical ones. Sometimes, there exists a combination of these damage modes.

\section{Damage Assessment of CFST Columns under Blast Loading}

4.1. Damage Criterion. As discussed previously, the CFST column subjected to blast loads may undergo flexural damage, shear damage, and localized damage; thus the damage criterion for the column should be chosen carefully and the appropriate one is expected to be applicable to all the possible damage modes of the column. In this paper, the damage criterion based on the residual axial load capacity is adopted for CFST columns due to the following reasons: (1) the structure column is primarily designed to carry the axial load and the axial load capacity of it reflects both its global properties and material characteristics; (2) the commonly used deformation-based damage criterions, that is, the support rotation, lateral deflection, and ductility, may not be appropriate for the evaluation of localized damage of the column; and (3) the residual axial load capacity of the columns is an explicit metric of the damage imparted and it also provides information in assessing the collapse possibility of a blast damaged column.

The damage index adopted herein is based on the index from Shi et al. [20] and is expressed as

$$
D_{c}=1-\frac{P_{\text {residual }}}{P_{\max }},
$$

where $D_{c}$ is the damage degree of CFST columns, $P_{\text {residual }}$ is the residual axial load capacity of the column after blast loads, and $P_{\max }$ is the maximum axial load capacity of the column prior to blast loading. Values of $D_{c}$ vary between 0 (i.e., no loss of capacity) and 1.0 (i.e., complete loss of capacity). Note that, in the paper by Shi et al. [20], the maximum axial load capacity of an undamaged column is calculated 


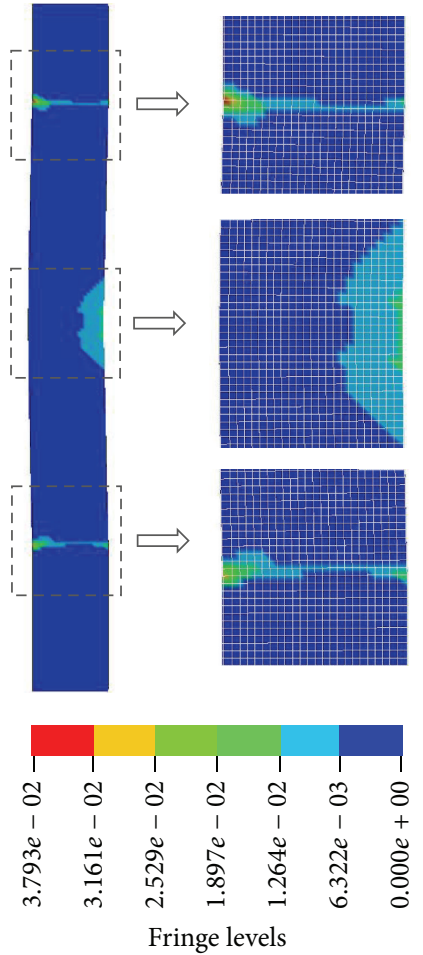

(a) CFST column

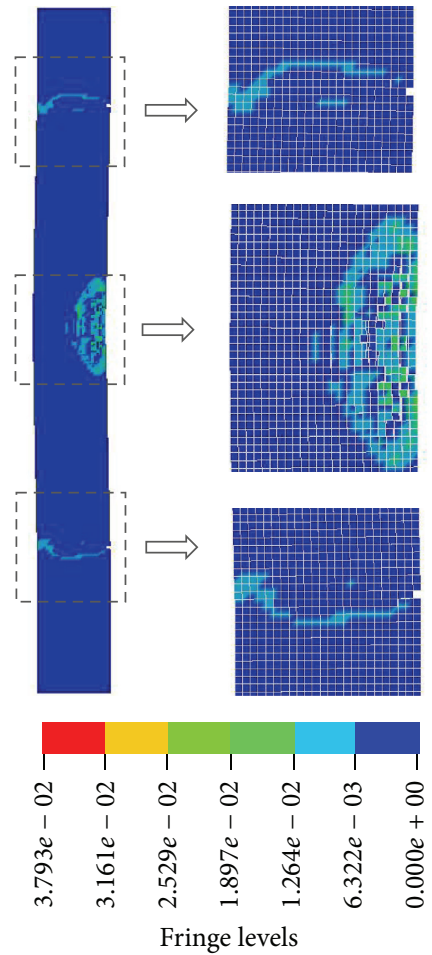

(b) Infill concrete

FIgURE 7: Flexural damage mode of CFST column under blast loading.

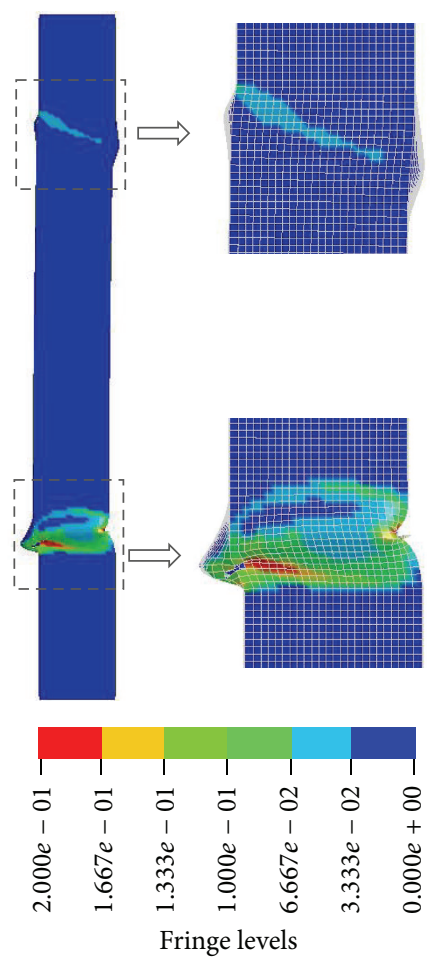

(a) CFST column
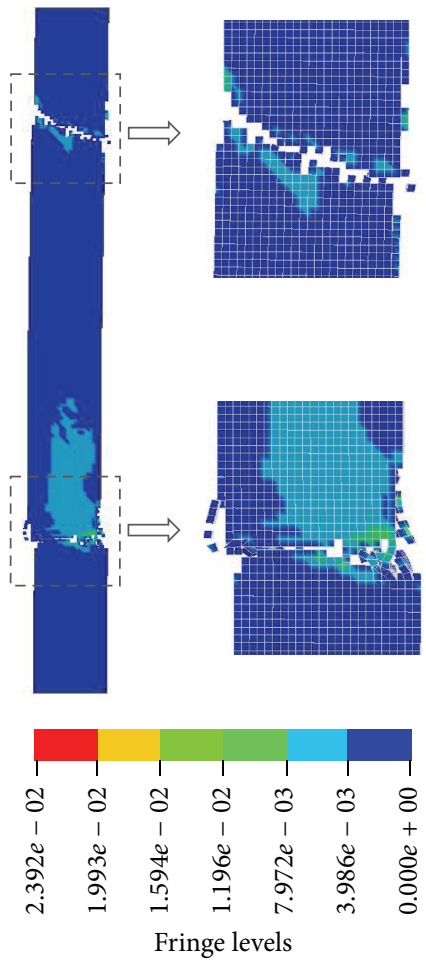

(b) Infill concrete

FIGURE 8: Shear damage mode of CFST column under blast loading. 


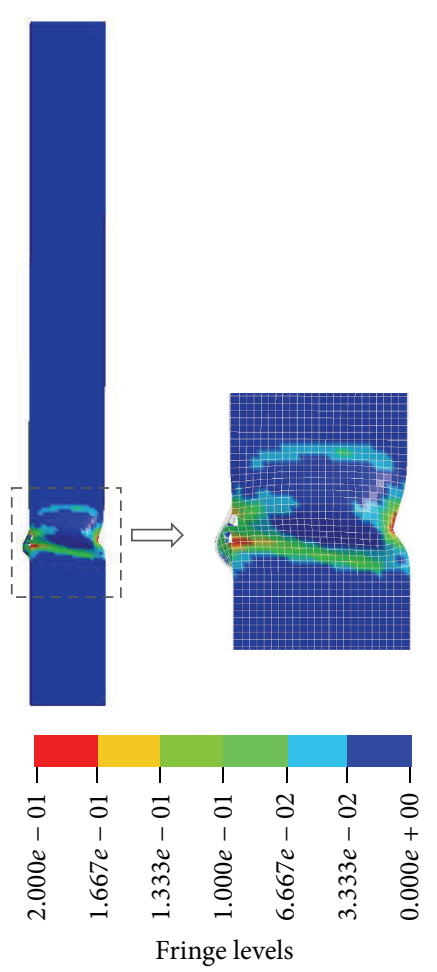

(a) CFST column
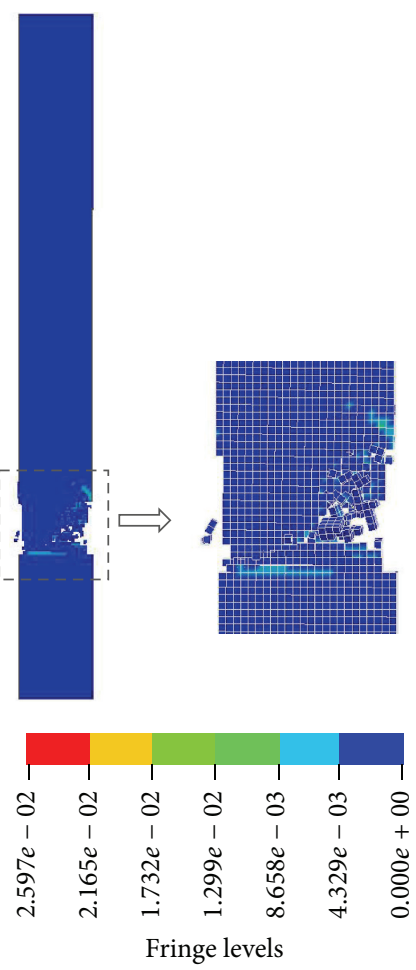

(b) Infill concrete

FIgURE 9: Localized damage mode of CFST column under blast loading.

with the provided equation from the standard design code, which however may lead to the values of $D_{c}$ below 0 in some cases. Therefore, both $P_{\text {residual }}$ and $P_{\max }$ are determined from numerical simulation in this study. Here $P_{\text {residual }} / P_{\max }$ is also termed as the residual capacity index (RCI) used by Wu et al. [22] and Crawford et al. [23] to assess the damage level of steel reinforced concrete (SRC) columns and reinforced concrete (RC) columns subjected to blast loads.

It is noted that if the ratio of the service axial load to maximum axial load capacity of the column is denoted as $n$, then a column whose $D_{c}$ is greater than $(1-n)$ is considered as failed or collapsed, since its residual axial load capacity is not sufficient for the service axial load.

\subsection{Steps for Damage Assessment of CFST Columns}

Step 1 (derivation of $P_{\max }$ ). During this step, the linearly increasing axial load is applied on the column head until the column collapses; then $P_{\max }$ is determined as the maximum axial load that the column can withstand.

Step 2 (derivation of $P_{\text {residual }}$ ). Three substeps as follows are required to obtain $P_{\text {residual }}$ : (1) before blast loading, a linearly increasing axial load up to the service axial load is imposed on the column; (2) blast loads are applied over the front face of the column with the service axial load being constant, and calculation is stopped when the damaged column approaches static equilibrium; (3) a linearly increasing axial load is imposed on the top of the damaged column until it collapses; then $P_{\text {residual }}$ is determined as the peak of the axial load that the damaged column can bear.

Step 3 (determination of $D_{c}$ ). Substitute the values of $P_{\max }$ and $P_{\text {residual }}$ into (7) to obtain $D_{c}$.

4.3. Parameters Studied. In this section, effects of several key parameters on the damage degree of CFST columns are analyzed. These parameters include the scaled standoff distance, height of burst, explosive mass, column depth, column width, column steel ratio, and axial load ratio, as listed in Table 4, in which a contrast case is generated by changing one of the parameters considered in the benchmark case while keeping other parameters unchanged. Note that, in each case, varied scaled standoff distances are considered so that the effects aforementioned parameters on the damage degree of columns within different blast loading regimes can be assessed.

4.3.1. Effect of Scaled Standoff Distance Z. The numerical simulation results show that $D_{c}$ of CFST columns decreases with the increasing scaled standoff distance, regardless of other parameters. This is because column damage is affected by the peak overpressure and impulse of the blast wave [21], and both of them drop with the rising scaled standoff distance, which results in a small degree of column damage.

4.3.2. Effect of Height of Burst $H_{B}$. It is difficult to characterize the effect of $H_{B}$ on the damage degree of the column. On 
TABLE 4: Parameters used in the numerical parametric study.

\begin{tabular}{|c|c|c|c|c|c|c|c|}
\hline Parameters & $Z\left(\mathrm{~m} / \mathrm{kg}^{1 / 3}\right)$ & $H_{B}(\mathrm{~m})$ & $M(\mathrm{~kg})$ & $d(\mathrm{~m})$ & $w(\mathrm{~m})$ & Steel ratio $\alpha^{*}$ & Axial load ratio $n$ \\
\hline Benchmark case & $0.18-0.50$ & 0 & 50 & 0.6 & 0.6 & 0.13 & 0.35 \\
\hline Contrast cases & $0.15-0.90$ & 1.85 & 250,500 & $0.9,1.2$ & $0.9,1.2$ & $0.16,0.19$ & $0.50,0.65$ \\
\hline
\end{tabular}

${ }^{*} \alpha=A_{s} / A_{c} ; A_{s}$ and $A_{c}$ are the cross-sectional areas of steel tube and infill concrete, respectively.

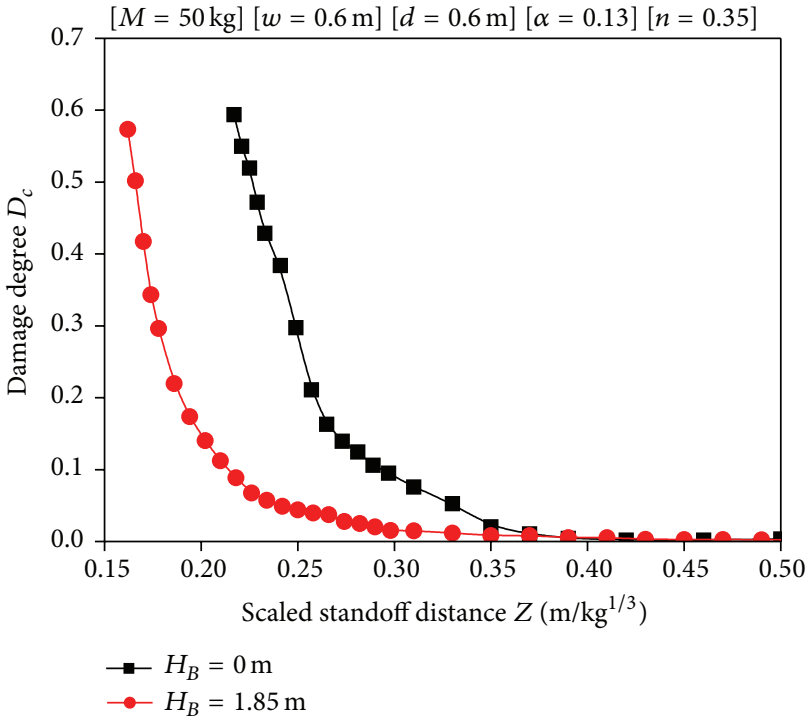

FIGURE 10: Effects of height of burst on the damage degree.

one hand, when $H_{B}$ nears zero, the initial blast wave is immediately reflected and reinforced by the ground. On the other, the mid-height of the column is expected to surfer the most severe damage due to lack of transverse support. Consequently, as shown in Figure 10, surface burst results in severer damage to the column than that caused by explosion at column mid-height $\left(H_{B}=1.85 \mathrm{~m}\right)$ especially when the standoff distance is small. The effects of $H_{B}$ on the damage degree of the column are insignificant at large scaled distances, because both the overpressure and impulse on the column are relatively small in these cases.

4.3.3. Effect of Explosive Mass M. Figure 11 shows the effects of explosive mass on the damage degree of the column. Inspections of the figure show that $D_{c}$ rises with $M$ for the same scaled standoff distance, indicating that CFST column is impulse-sensitive since explosive with larger mass has relatively more impulse for the column.

4.3.4. Effects of Column Width $w$ and Depth d. Effects of column depth and width on $D_{c}$ are shown in Figure 12. Compared with the reference column $(w=0.6 \mathrm{~m}, d=0.6 \mathrm{~m})$, columns with larger width and depth tend to have lower damage degrees, because expanding column width and depth produces a larger cross section for attenuation of the stress waves density and contributes to enhancement of the shear resistance as well as flexural strength of the column. However, it is found that columns with the same cross section area but different width and depth have varied damage degrees and

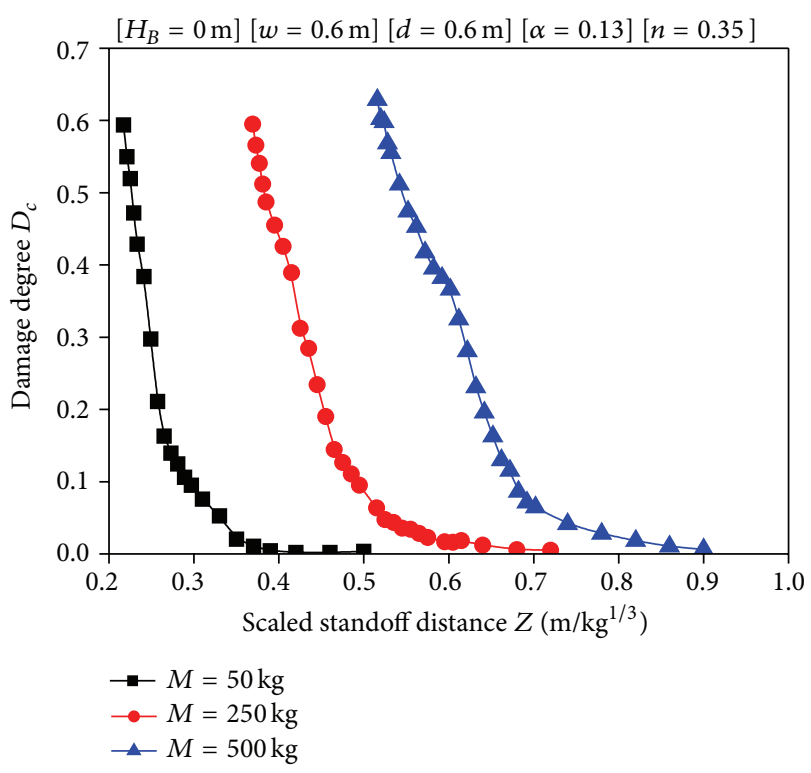

FIGURE 11: Effects of explosive mass on the damage degree.

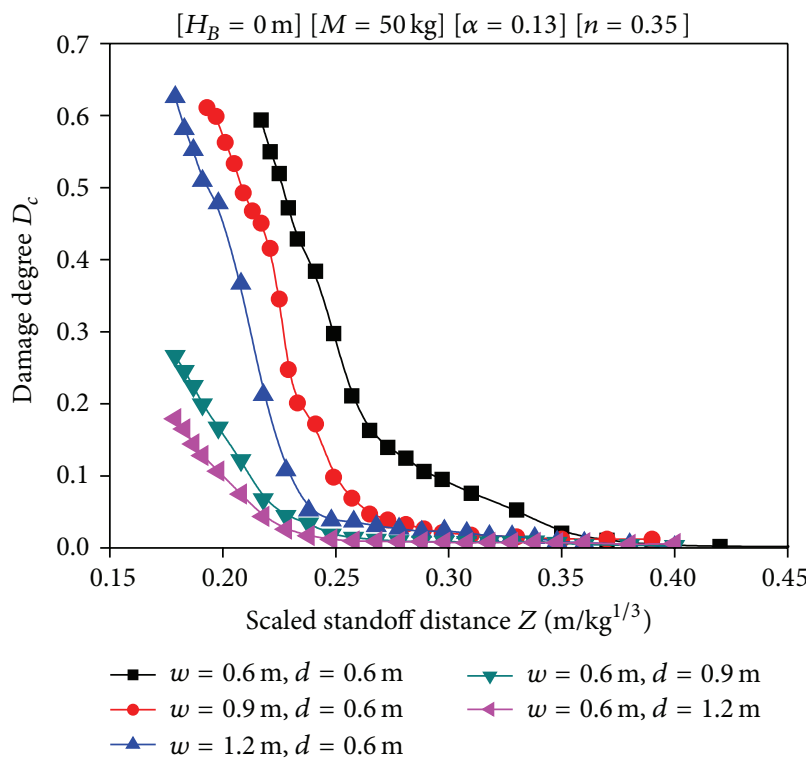

FIGURE 12: Effects of width and depth on the damage degree.

that, compared with increasing the column width, increment of the column depth is more effective in reducing the column damage degree. This is because enlarging the column width simultaneously results in a rise of blast loads acting on the column, which balances out the enhancement of column blast resistance to some extent. 


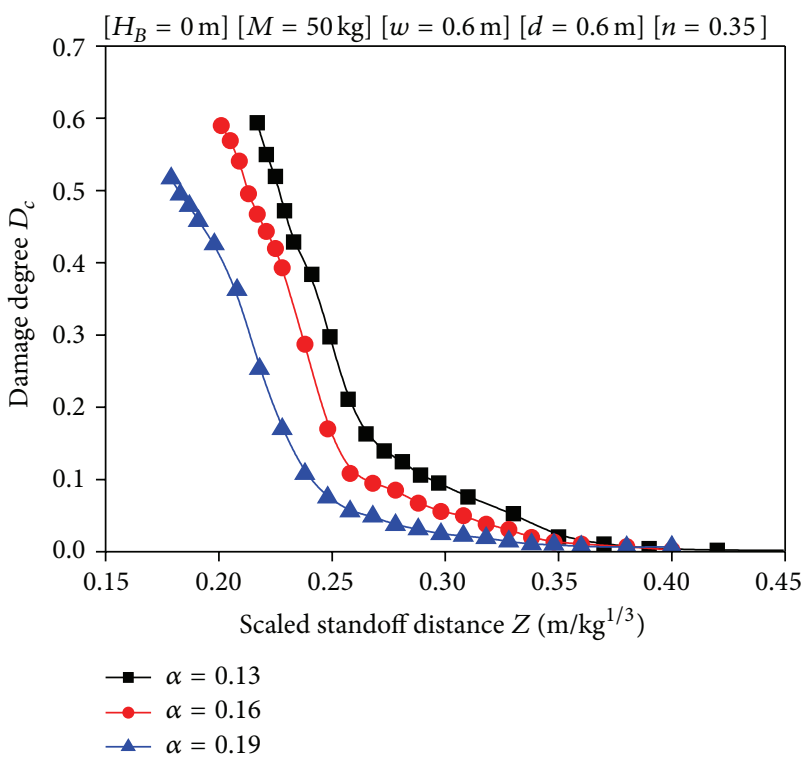

FIGURE 13: Effects of steel ratio on the damage degree.

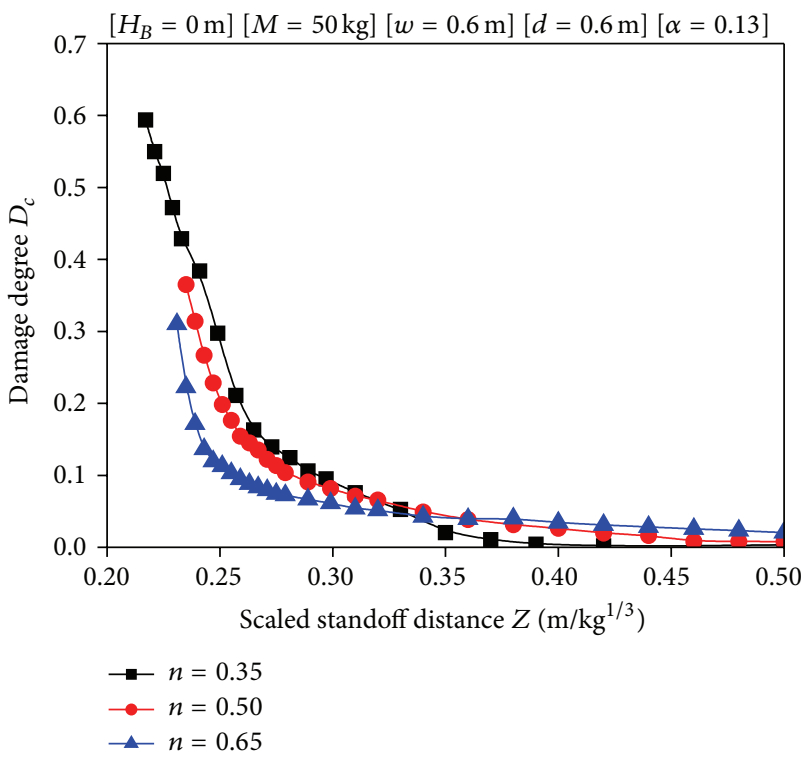

FIGURE 14: Effects of axial load ratio on the damage degree.

4.3.5. Effect of Column Steel Ratio $\alpha$. As shown in Figure 13, $D_{c}$ drops with the rising steel ratio. This is expected because increasing $\alpha$ means a larger steel area and better confinement of infill concrete, which will enhance the shear and bending strength of the column as well as its resistance to localized damage.

4.3.6. Effect of Column Axial Load Ratio n. Effects of axial load ratio on $D_{c}$ are shown in Figure 14. Inspection of the figure reveals that axial load ratio has dual influences on column damage. When the scaled standoff is small, the column with a larger axial load ratio has lower damage degree. This is because the column under small scaled standoff is likely to suffer localized damage and shear damage, and a higher axial load will restrain the cracking and crushing of concrete, which enhances the resistance of the column to localized damage and shear damage. In contrast, at a large scaled standoff distance, the column with larger axial load ratio has higher damage degree. The reason is that, with the increase of the scaled standoff distance, the column tends to suffer flexural damage which is related to its moment capacity and ductility. The larger the moment capacity and ductility are, the lower the damage degree is. For the CFST column studied in this section, the axial load ratio at the maximum moment capacity is 0.22 , which is derived by the methods from Choi et al. [1]. According to the axial load-bending moment (P-M) interactions, the moment capacity of the CFST column will decrease when $n$ rises from 0.35 to 0.60 . Moreover, a rising axial load will reduce the ductility of the CFST column.

4.4. Empirical Equations for Determining the Damage Degree of CFST Columns. The parametric study revealed the significance of parameters affecting the damage degree of CFST columns. Through the multivariable regression analysis, an empirical equation is proposed in terms of various parameters to predict the damage degree and is expressed as follows:

$$
\begin{aligned}
D_{c} & =\left[-15.05 \ln \left(\frac{M}{50}\right)+16.50\left(\frac{w}{0.6}\right)-32.42\left(\frac{d}{0.6}\right)\right. \\
& -1316.25 \alpha+153.49 n+250.11] \\
& \cdot e^{\left[-6.48 \ln (M / 50)+5.33(w / 0.6)-10.91(d / 0.6)^{-3.73}-12.30 \alpha+12.92 n+26.81\right] Z} .
\end{aligned}
$$

The comparisons of the proposed equation with the analytical results are shown in Figures 15(a)-15(f). The scatters denote the analytical results, and the solid lines represent the proposed equation. Observation of these figures shows that the proposed curves are close to the analytical results for most cases. The effects of height of burst on the damage degree of CFST columns are not reflected by (8) due to the lack of blast data in the lower height of the column which are limited in the ConWep model and will be supplemented in the further studies.

\section{Conclusions}

This paper presents a $3 \mathrm{D}$ numerical model to investigate the damage modes and damage assessment of CFST columns. Based on the numerical analysis results, the following conclusions can be drawn.

CFST columns under blast loading may undergo the global flexural damage and shear damage as well as localized damage. Flexural damage and shear damage of the column are mainly attributed to the deformation and internal force of the whole member, whilst the localized damage is dominated by the failure of infill concrete and steel tube in the vicinity of the explosion.

The damage criterion based on the residual axial load capacity is adopted for assessing the degree of CFST columns damage to blast loads. Through parametric studies, it is found that the damage degree of CFST columns decays nearly exponentially with the increasing scaled standoff distance. 

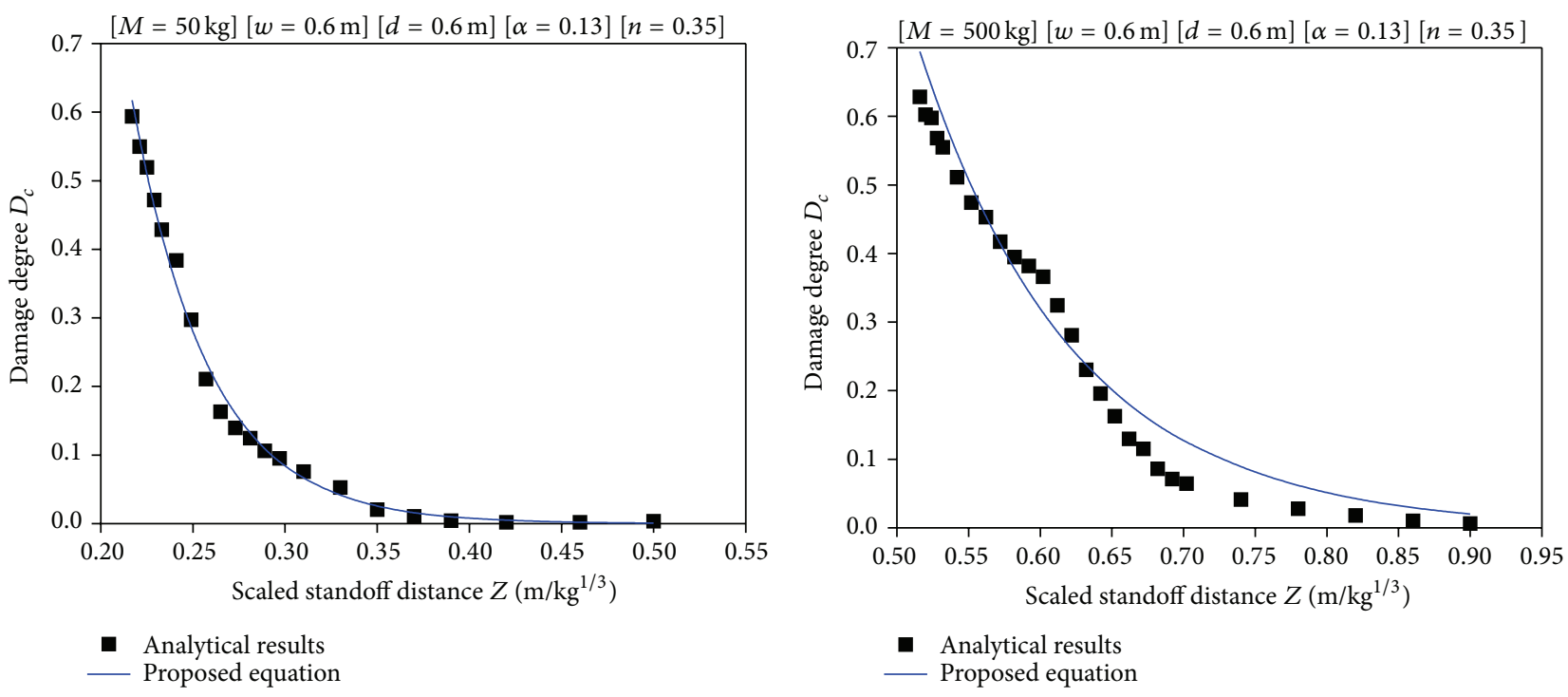

(a)

(b)
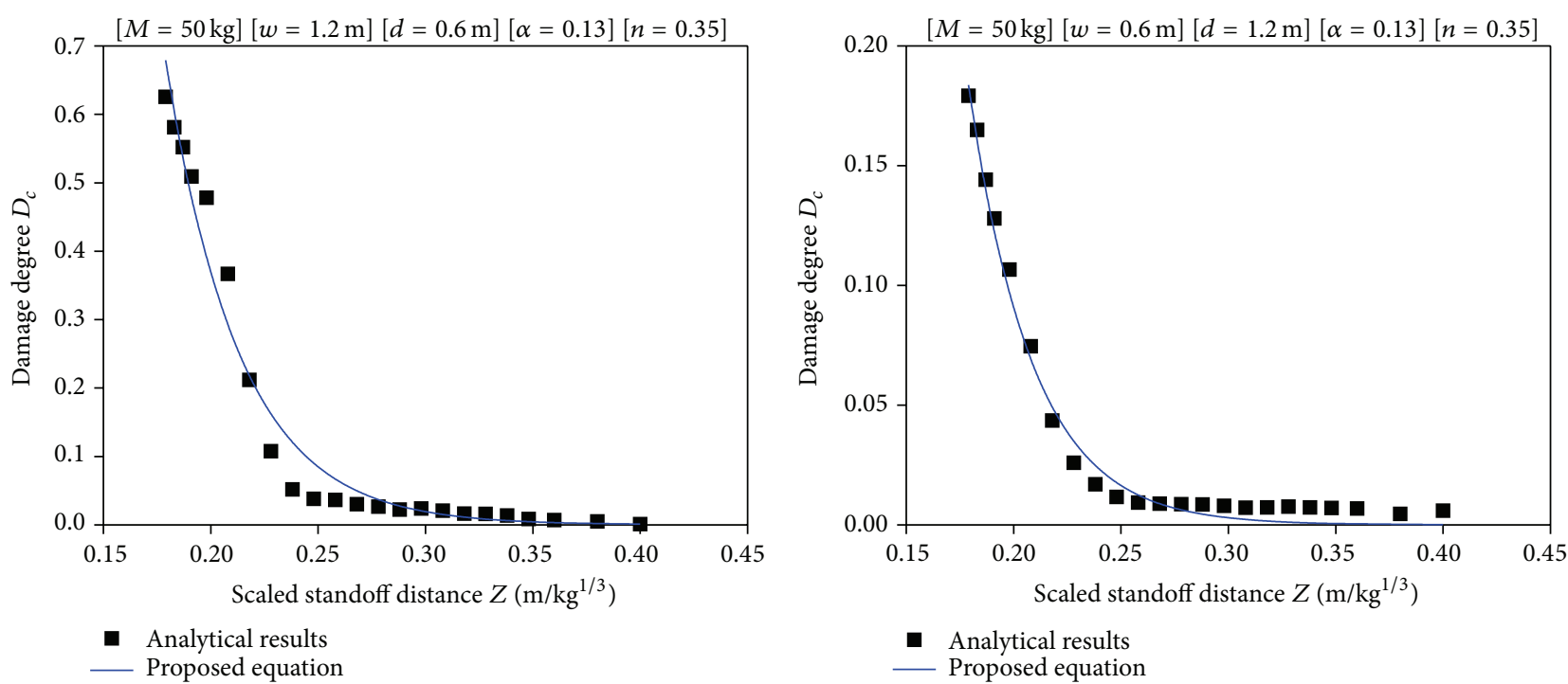

(c)

(d)
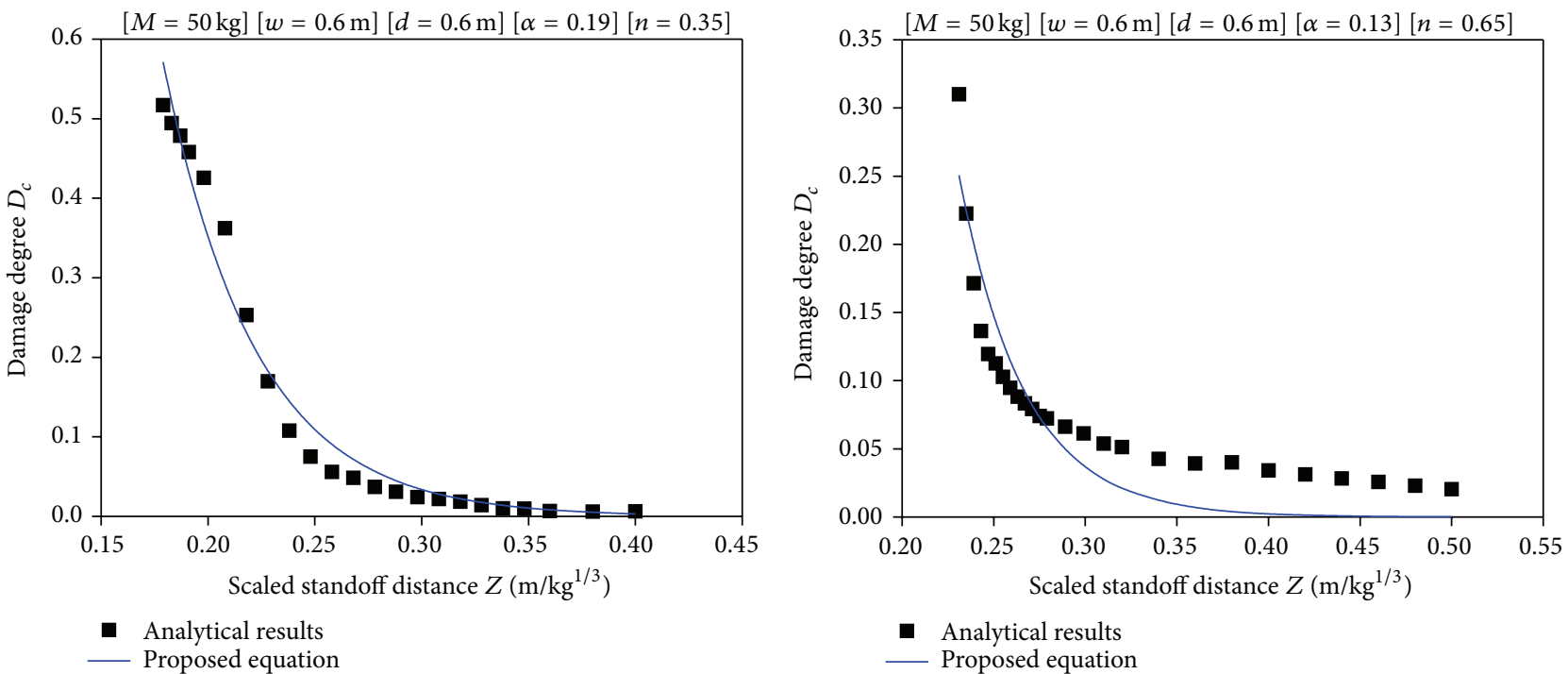

(e)

FIGURE 15: Comparison of analytical results with the proposed curves. 
For the same scaled standoff distance, surface burst results in severer damage to the column than that caused by explosion at column mid-height, and the damage degree increases with the rising explosive mass and decreases with column depth and width and steel ratio. Increasing the axial load enhances the resistance of the column against localized damage and shear damage, while the effects of axial load on flexural damage depend on the axial load-bending moment (P-M) interactions of the column.

An equation is derived by fitting the results of parametric studies to estimate the damage degree of CFST columns. Typical examples confirm that the proposed equation well represents the variation of the column damage degree. However, future experiments can be conducted for investigating the effects of other parameters on the damage degree of CFST columns.

\section{Conflict of Interests}

The authors declare that there is no conflict of interests regarding the publication of this paper.

\section{Acknowledgments}

The research described in this paper was financially supported by Achievement Transfer Program of Institutions of Higher Education in Chongqing under Grant no. KJZH14220.

\section{References}

[1] Y.-H. Choi, D. A. Foutch, and J. M. LaFave, "New approach to AISC P-M interaction curve for square concrete filled tube (CFT) beam-columns," Engineering Structures, vol. 28, no. 11, pp. 1586-1598, 2006.

[2] Y.-H. Choi, K. S. Kim, and S.-M. Choi, "Simplified P-M interaction curve for square steel tube filled with high-strength concrete," Thin-Walled Structures, vol. 46, no. 5, pp. 506-515, 2008.

[3] T. Krauthammer, Modern Protective Structures, Taylor \& Francis Group, New York, NY, USA, 2008.

[4] S. C. Fujikura, M. Bruneau, and D. Lopez-Garcia, "Experimental investigation of blast performance of seismically resistant concrete-filled steel tube bridge piers," Tech. Rep. MCEER-070005, University at Buffalo, Buffalo, NY, USA, 2007.

[5] S. Fujikura, M. Bruneau, and D. Lopez-Garcia, "Experimental investigation of multihazard resistant bridge piers having concrete-filled steel tube under blast loading," Journal of Bridge Engineering, vol. 13, no. 6, pp. 586-594, 2008.

[6] G. Li, H. Qu, T. Yang, Y. Lu, and S. Chen, "Experimental study of concrete-filled steel tubular columns under blast loading," Jianzhu Jiegou Xuebao, vol. 34, no. 12, pp. 69-76, 2013 (Chinese).

[7] A. M. Remennikov and B. Uy, "Explosive testing and modelling of square tubular steel columns for near-field detonations," Journal of Constructional Steel Research, vol. 101, pp. 290-303, 2014.

[8] T. Ngo, D. Mohotti, A. Remennikov, and B. Uy, "Numerical simulations of response of tubular steel beams to close-range explosions," Journal of Constructional Steel Research, vol. 105, pp. 151-163, 2015.

[9] F. R. Zhang, C. Q. Wu, H. W. Wang, and Y. Zhou, "Numerical simulation of concrete filled steel tube columns against BLAST loads," Thin-Walled Structures, vol. 92, pp. 82-92, 2015.
[10] F. Zhang, C. Wu, X. Zhao, Z. Li, A. Heidarpour, and H. Wang, "Numerical modeling of concrete-filled double-skin steel square tubular columns under blast loading," Journal of Performance of Constructed Facilities, vol. 29, no. 5, Article ID B4015002, 2015.

[11] Livermore Software Technology Corporation, LS-DYNA Theoretical Manual, Livermore Software Technology Corporation, Livermore, Calif, USA, 1998.

[12] G. R. Cowper and P. S. Symonds, "Strain-hardening and strainrate effects in the impact loading of cantilever beams," Tech. Rep. AD144762, Office of Naval Research, Arlington, Va, USA, 1958.

[13] T. J. Holmquist, G. R. Johnson, and W. H. Cook, "A computational constitutive model for concrete subjected to large strains, high strain rates, and high pressures," in Proceedings of the 14th International Symposium on Ballistics, Quebec City, Canada, September 1993.

[14] Q. Fang and J. Zhang, "Three-dimensional modelling of steel fiber reinforced concrete material under intense dynamic loading," Construction and Building Materials, vol. 44, pp. 118-132, 2013.

[15] Y. Li, F. Lin, X. L. Gu, and X. Q. Lu, "Numerical research of a super-large cooling tower subjected to accidental loads," Nuclear Engineering and Design, vol. 269, pp. 184-192, 2014.

[16] J. Li and H. Hao, "Numerical study of concrete spall damage to blast loads," International Journal of Impact Engineering, vol. 68, pp. 41-55, 2014.

[17] G. Randers-Pehrson and K. A. Bannister, "Airblast loading model for DYNA2D and DYNA3D," Tech. Rep. ARL-TR-1310, Army Research Laboratory, Adelphi, Md, USA, 1997.

[18] Livermore Software Technology Corporation, LS-DYNA Keyword User's Manual (Version 971 R6.1.0), Livermore Software Technology Corporation, Livermore, Calif, USA, 2012.

[19] CECS, "Technical specification for structures with concretefilled rectangular steel tube members," CECS 159:2004, China Association for Engineering Construction Standardization, Beijing, China, 2004 (Chinese).

[20] Y. Shi, H. Hao, and Z.-X. Li, "Numerical derivation of pressureimpulse diagrams for prediction of RC column damage to blast loads," International Journal of Impact Engineering, vol. 35, no. 11, pp. 1213-1227, 2008.

[21] P. D. Smith and J. G. Hetherington, Blast and Ballistic Loading of Structures, Butterowrth-Heinemenn, Oxford, UK, 1994.

[22] K.-C. Wu, B. Li, and K.-C. Tsai, "The effects of explosive mass ratio on residual compressive capacity of contact blast damaged composite columns," Journal of Constructional Steel Research, vol. 67, no. 4, pp. 602-612, 2011.

[23] J. E. Crawford, K. B. Morrill, and J. M. Magallanes, "Protective design for columns against close-in blast effects," in Proceedings of the Structures Congress, Boston, Mass, USA, April 2014. 


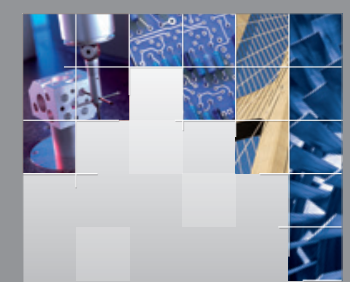

\section{Enfincering}
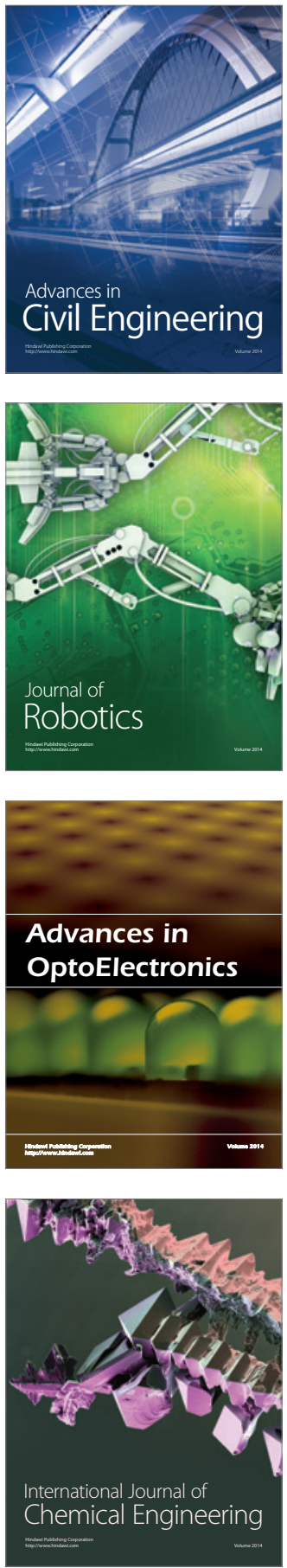

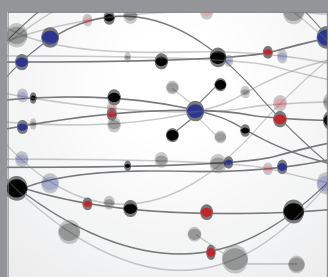

The Scientific World Journal

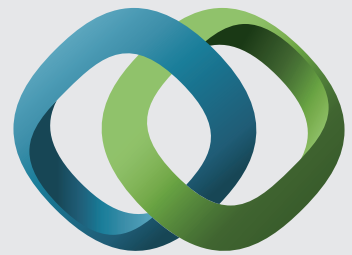

\section{Hindawi}

Submit your manuscripts at

http://www.hindawi.com
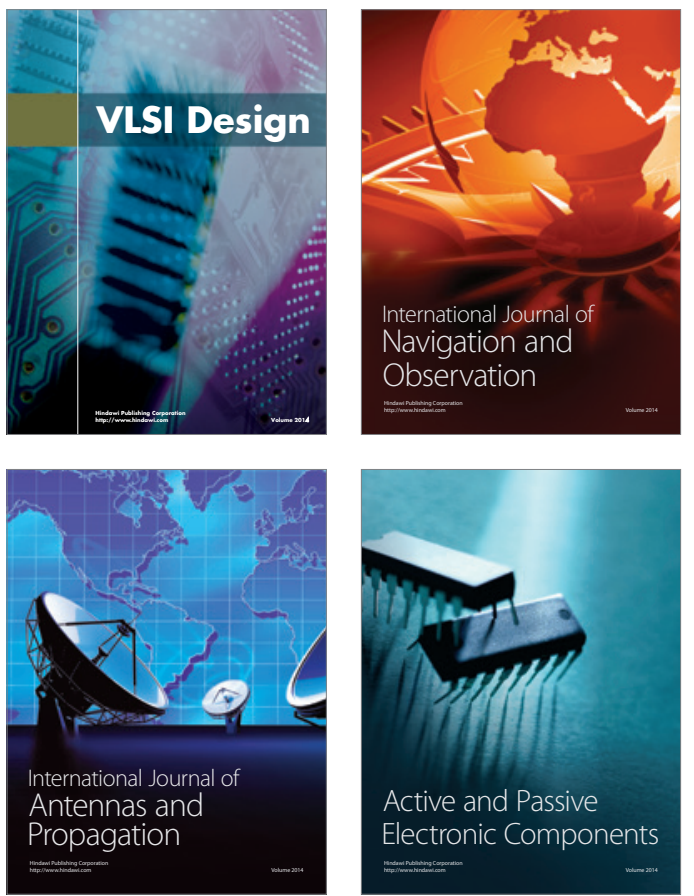
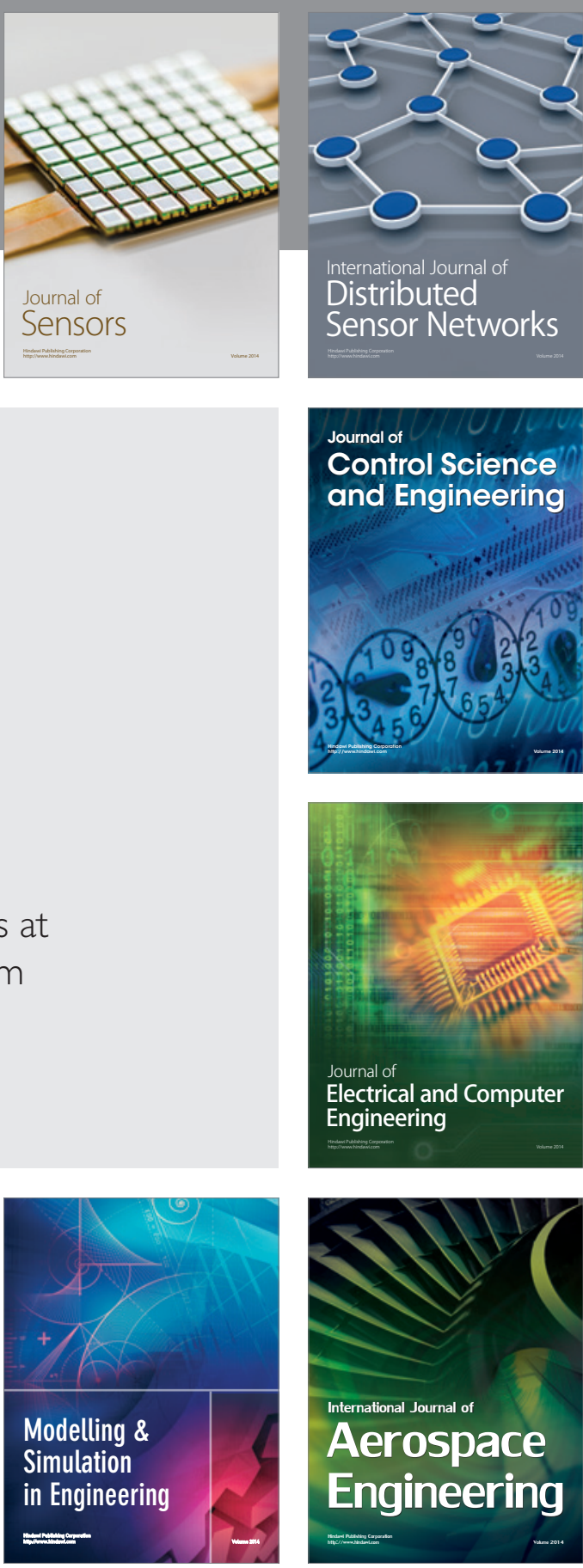

International Journal of

Distributed

Sensor Networks

Journal of

Control Science

and Engineering
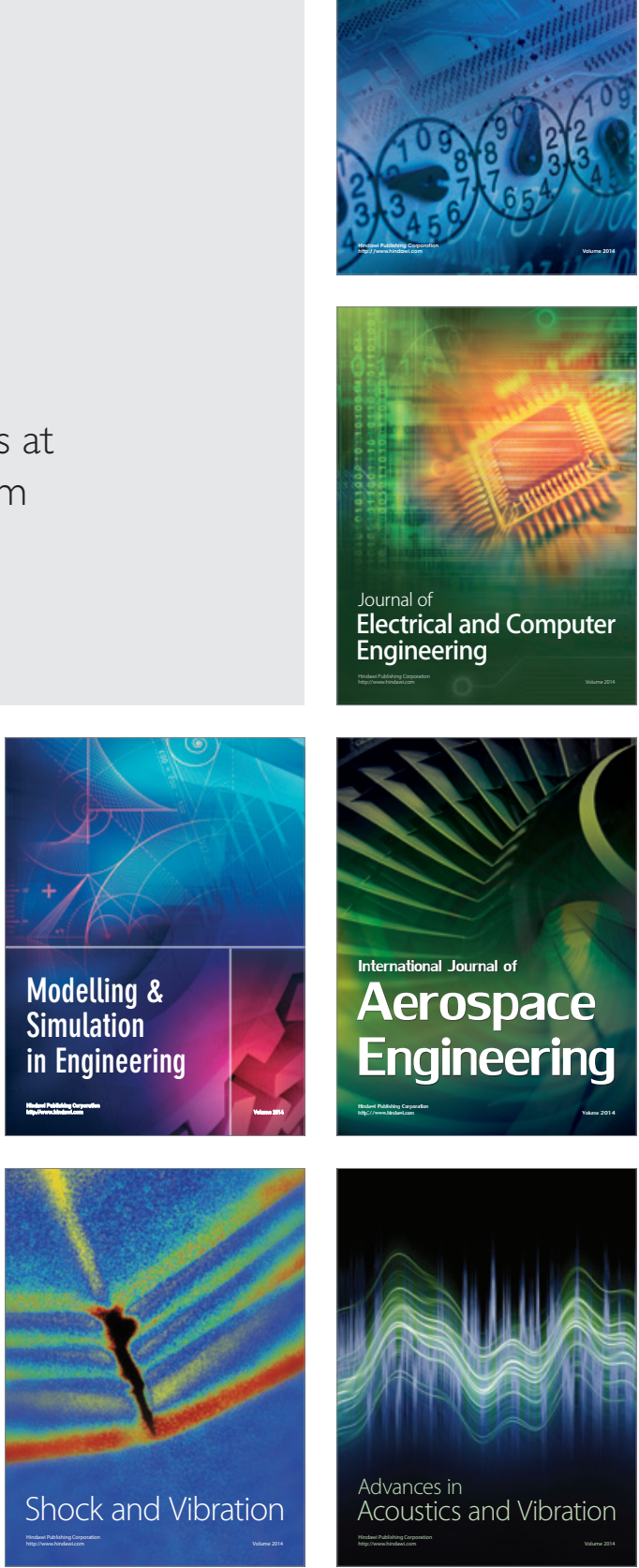